\title{
IMPACT OF CONFORMITY, COMMITMENT AND MANAGEMENT STYLE ON AN INFORMATION SYSTEM PROJECT
}

\author{
Bassam A. Hussein, Kristin H. Hafseld \\ Department of Production and Quality Engineering \\ The Norwegian University of Science and Technology \\ 7491 Trondheim, Norway \\ bassam.hussein@ntnu.no
}

\begin{abstract}
This paper studies the impact of organizational influences on the development of a major information system project at a governmental organization in Norway. The results suggest that strong conformity pressure and weak affective organizational commitment among end users, in addition to the lack of project management competence in the organization were contributing factors that led to complications, overspending, delays, and reworks. The findings also indicate that a combination of an authoritarian style and resistance to change have impacted on the organization ability to effectively involve, prepare and commit end-users to the project and to the changes it will create in the organization. In addition to these cultural factors, there was also lack of top management support, which has directly impacted the organization's ability to provide support and resources. Copyright (C) Research Institute for Intelligent Computer Systems, 2014. All rights reserved.
\end{abstract}

Keywords: commitment; conformity; user involvement; organizational factors; organizational culture; information systems projects; case study.

\section{INTRODUCTION}

This paper is based on a case study that describes the development and deployment of a large-scale office management system in a governmental organization. For the purpose of adhering to the informant's request of full anonymity, we shall refer to this organization hereafter by "the Ministry". The Ministry has a threefold structure: 1) the political body, representing the interests, aspirations, and objectives of the Ministry's political leadership; 2) the administrative body representing the rules, regulations, and constraints set by civil servants; and 3) the professional structure, representing, the needs, expectations, workflow, and processes of the experts assigned to different posts in the Ministry. These bodies may have divergent, and to a certain degree conflicting, expectations, wants, needs, and working cultures. The diverse range of expectations combined with incompetent management of information systems (IS) projects, together with organizational factors that impact on the

This paper is a revised and expanded version of a paper entitled 'Impact of organizational factors on information system project' presented at 7th IEEE International conference on Intelligent Data Acquisition and Computer Systems: Technology and Applications, Berlin, September 2013 [1] organization's ability to manage the development and deployment of the new office management - has led to project complications, overspending, delays, and frustration among the diverse groups that were supposed to be using the system.

The purpose of the paper is to find out how and to what extent these organizational influences have shaped the results of this project through their influence on system development processes and procedures, such as the allocation of resources, the use of a structured approach to requirement elicitation, decision-making, and end-user involvement, creating commitments and aligning users in a large-scale information system project that was initiated in 2002 and is still yet to be completed. The paper also aims to present countermeasures that have been implemented in order to enhance end users' involvement, and to better prepare the organization for the intended changes to working processes and methods.

\subsection{ORGANIZATIONAL INFLUENCES}

Organizational Influences is an umbrella concept that refers to factors in the social and organizational context that impact the project setting. Organizational influences are usually reflected in numerous factors, including style, structure, 
competence, shared values, norms and beliefs, policies and procedures, the view of relationships with authority, and work ethics, to mention but a few [2]. This paper only considers the organizational influences in the project owner organization. The term "project owner organization" is used in this paper to refer to the organization that ordered the system to be developed and implemented, and the one who provided the necessary financial resources. The owner organization's main tasks are to keep the project aligned with the organization's strategy; maintain a focus on the realization of benefits; provide feedback; commit necessary resources; create commitments; ensure involvement oversee the project's execution; and oversees the project's organization.

Mei-Yung, et al. [3] argue that affective commitment improves the project performance because people are more attached and involved in the project, and also want to stay in the organizational for the particular project. Fowler and Horan [4] identify a combination of top management commitment and project team commitment as a force driving the successful development of IS projects. Pinto and Prescott [5] identified top management support as a critical success factor and suggested its dominance in the planning phase of the project life cycle. McLeod and MacDonell [6] emphasize the importance of top management in projects as it plays various roles in the organization, for example influencing attitudes, creating a positive context for change, overseeing the development of the project, and ensuring the availability of resources.

In the project management literature, there is also a consensus that involving end-users during system development is paramount to ensuring project success [6-8]. Several factors relate to the inability of project owner organizations to be able to accomplish all these tasks. For instance, a project manager with a highly participative style in a rigidly hierarchal organization is likely to encounter challenges [2]. Findings by Basu, et al. [9] suggest that the involvement of top management in the owner organization is of paramount importance for successful implementation of major IS projects. Their involvement seems to be even more important than the project organisation's involvement.

Hong and Kim [10] demonstrated that, as far as major projects are concerned, it is not always the case that the organization is prepared or adapted either culturally or organizationally - for the project's delivery. They have shown that there are few organizations that have a structure equipped for the sorts of changes associated with the introduction of large, complex projects. Therefore, project owner organizations should consider the project as abroad introduction of organizational changes rather than technical software installation. A project that aims to introduce greater solutions requires a change in the organisation's socio-technical system. The ability to share knowledge and information is also characteristic of an organisation's work culture. Milne [11] emphasized that one of the biggest challenges for a knowledge organization is information sharing. Knowledge sharing is, according to the author, "the fundamental requirement of a knowledge-based organization. In particular, organizations where there is a fortified culture among staff to safeguard information, rather than sharing it with others." Hussein, et al. [12] have shown that project organization ability to maneuver, conduct early planning and align project is largely dependent on high-level organizational factors, in terms of willingness to free up resources so that they can contribute in the early phase. It depends also on top-management support to the project.

Today, an organization in which information is spread internally as quickly as possible has a competitive advantage. A challenge for any knowledge organization is how to build a culture in which the dissemination of information is the norm, rather than the safeguarding of it. According to Milne [11] incentive systems help to motivate employees to share information, and thus build a more open and inclusive culture. Organisational culture can be viewed as a symbolic system of learned and shared sets of meanings that provide patterns for behavior within an organizational setting [13]. Organisational culture influences communication between end users and developers; an organizational culture based on consensus encourages communication and conflict resolution during the requirement elicitation stage as emphasized by [14].

As the above theoretical approaches show, organizational influences such as structure and culture affect an organisation's ability to structure and manage their users' involvement, to provide support and resources, to align the project upwards and downwards.

\subsection{CASE STUDY: THE OFFICE MANAGEMENT SYSTEM}

The Ministry realized that more effort should be exerted in communicating effectively with the outside world. It was essentially external conditions and factors that "forced" the Ministry to evaluate and seek new technologies in the first place. In 1999, a number of initiatives to strengthen the use of information technology in the Ministry were proposed. Among these initiatives was the introduction of an electronic office management system. The core business of the Ministry is 
gathering, producing, and disseminating information to the right recipients in a timely fashion. There are therefore huge amounts of memos, notes, and documents produced and channeled each year. As an example, in 2002 alone, the Ministry produced around 98,000 documents that were deemed archiveworthy. There have been great expectations among the employees regarding the new office management system. Employees were promised that the new system would lead to more efficient and faster processing, easier archiving, and prompter document searches.

In 2001, the Ministry signed a contract with an external provider tasked with developing and installing the system. Between summer 2002 and winter 2003, the work included the documentation of existing work processes and procedures in the Ministry. Our findings have shown that neither the employees nor the development department were truly involved in this phase. In addition, the project was managed by a project manager from the system provider who had no genuine knowledge of the Ministry's work processes, culture, or power structure. This may suggest that the task of modeling the organization's work processes had been underestimated by both the project steering committee (who were representing the interests of the Ministry) and the IS provider. Our findings also indicate that the system was developed and tailored mainly to address the needs of one group of end users - namely, the archivists - and to a lesser extent to satisfy the needs and expectations of other classes of end users, including those who actually author and produce the documents. It is also evident that the Ministry failed to align end users to the fact that introducing this new system would also mean that these people would also need to change the way they collaborate and work together. The project failed in fostering this understanding among those who would actually be using the system when it was set for operation. According to the original project plan, a pilot version of the new office management system was scheduled to be launched in May 2003, before being introduced to the rest of the organization by the start of 2004. However, it was quickly discovered after introducing the pilot version that the system did not live up to expectations.

After this failed attempt, the task of documenting and modeling the work processes in the Ministry had to start over. This task was reworked from summer 2003 to April 2004. The system provider then claimed that the new solution was tailored to the Ministry's needs. However, it was quickly discovered that this was not true, and parts of this new system were in fact still under development. The system provider subsequently required the
Ministry to upgrade its information system infrastructure.

In autumn 2004, a prototype of the office management system was launched and ran in parallel to the Ministry's infrastructure upgrade. In the summer of 2005, an evaluation of the new system was carried out, and it was concluded that a full deployment of the new system should take place in spite of different interpretations of this evaluation. Many believed (including external experts) the system was not yet fully tested and had many "infant ailments". However, there was a lot of invested prestige in the project, and the project owner wanted to show "vigor." The decision to roll out the system was undertaken by the Minister himself despite counter recommendations, and so the implementation of the system was rushed through without additional testing. It seemed that the Ministry was very keen to introduce the information technology tools. The full deployment of the new office management system began in September 2005, and by June 2006 it was available to all executive officers and managers in the Ministry.

From its deployment in June 2006 until 2012, the system faced massive opposition and criticism from employees at all levels in the organization. An evaluation of the system by end users contained three major operational problems: 1) the system was not user-friendly; 2) the system was hard to navigate, and documents were hard to find; and 3 ) the system was not intuitive. Through several user surveys, the employees indicated that the new system was practically useless in their daily work. Despite improvements and simplifications in recent years, end users' criticisms have not subsided, while the majority of the Ministry's staff only use the system occasionally. The number of documents that were archived drastically reduced from 98,000 in 2002 to 66,000 in 2010.

Large amounts of resources - both human and financial - have been used to solve challenges in the wake of the massive criticism and resistance from users. However, after 10 years of trial and error, and an estimated price tag of 150 million Norwegian kroner (equivalent of around 20 million Euros), the project has still failed to meet the expectation of end users.

In many ways this case study reflects how the Ministry organizes and runs projects, wherein projects lack effective adherence to the structured requirements of the management process, including a lack of stakeholder profiling, no robust processes or mechanisms for insuring tangible end-user involvement, a lack of measurability in achieving project objectives, and a lack of proper frames for measuring and evaluating project outcomes. 
It may also be noted that in 2012, the Ministry decided to abandon the entire system and instead selected another office management solution. For this purpose, a new project organization was established in 2012 headed by a newly appointed project manager who had extensive experience with the Ministry's working culture. The responsibility of the project was handed to the department of organizational development rather than human resources. Several measures have also been taken to better align the top management and end users to the project and its expected outcome.

In this paper we shall explore the underlying causes of the project's failure in relation to organizational influences using interviews with key stakeholders actively involved in the project. The paper also aims to present an outline for mitigation strategies that have been implemented by the new management to ensure the proper involvement of end users, and the better alignment of the project both upwards and downwards.

\subsection{LIMITATIONS OF THE STUDY}

This study is limited to identifying the organizational influences in the project owner organization. The paper does not address all possible factors that could impact on the project's outcome, such as people and actions, project contents, development processes, and environmental factors [6]. We should therefore acknowledge that other factors might have contributed to the problems and setbacks faced in this project. The research is also limited to solely examining one case study. Furthermore, the number of informants in the case study is quite limited, and we therefore have no strong evidence that the case is representative of all projects in the organization. On the other hand, the study could help both practitioners and decisionmakers to learn about some potential problem areas that might arise in large governmental organizations that have a strong line management focus.

The rest of the paper is organized as follows. Firstly, we shall describe the data collection method used in the paper, and provide an overview of the informants who have contributed to the research. A total of eight informants were interviewed: six of these informants were involved in the project in the period 2002-2011, and two informants have been involved in the project since 2012. Findings from the interviews will then be presented and discussed in relation to the extant project management literature. Some conclusions and recommendations will then be presented. The main purpose of the conclusions and recommendations will be to outline the major organizational influences found in the case study, and to outline a framework for addressing these influences in future projects at the Ministry.

\section{DATA COLLECTION}

To investigate the impact of organizational influences on project development and the means of addressing these influences, we have conducted two sets of eight semi-structured interviews. In the first round, we interviewed key project stakeholders who had been involved in the project in the period 20022010. The objective of the interviews was to collect the informants' perceptions of organizational influences in terms of the project's culture, style, organizational structure, decision-making, knowledge, and competence. In the second round, we interviewed two informants who were involved in leading the current project (2011-2013).

Each informant had about 60 minutes to talk about their experience within the project. However, they were encouraged to focus particularly on issues related to organizational influences in the Ministry that might have impacted performance and outcome. They were asked to talk about challenges they faced, especially in connection with the project, and were asked to illustrate these challenges with concrete examples. The interviews were conducted at a neutral location, such as cafe or in a meeting room, or by telephone due to traveling obligations. The informants requested full anonymity, as there is deep-seated skepticism of openness in the Ministry, particularly with regards to problematic issues; one informant eloquently stated that it is

$$
\text { "a painful subject to talk about." }
$$

The aim of the second round of interviews was to get the informants' perspectives on how the newly appointed leadership views the organizational influences, and to outline the main lessons learned from the first stage of the project. It was also important to get their opinions on the measures needed to reduce the impact of the organizational influences. The informants were selected based on their experience with the project, as shown in Table 1.

\section{FINDINGS}

The authors have not used any structured mechanism for analyzing the data collected through the interviews. However, during the first round of interviews, we have looked for aspects related to the following dimensions of organizational influence in the data: 1) organizational culture; 2) organizational structure and established practices; and 3) Project management competence in the organization. According to McLeod and MacDonell [6], these three dimensions constitute the organizational influences.

\subsection{CONFORMIST CULTURE}

All informants noted that the conformist working style in the Ministry stood as a challenge, and 
described it as a hindrance in connection to the organization's ability to perform. Work culture in the Ministry is characterized by valuing conformity and consensus. This is reflected among other things in the way public statements are made: everyone should have the opportunity to comment in order that the statement reflects the Ministry's collective position on a topic or issue.

Table 1: Informants' role in the project and the objective of the interviews

\begin{tabular}{|c|c|c|c|}
\hline period & Informant & Role & $\begin{array}{c}\text { Objective of } \\
\text { interview }\end{array}$ \\
\hline \multirow[t]{6}{*}{$\begin{array}{l}2001- \\
2011\end{array}$} & Informant 1 & $\begin{array}{l}\text { Involved in early } \\
\text { phase (user } \\
\text { representative) }\end{array}$ & \multirow{6}{*}{$\begin{array}{l}\text { Identify } \\
\text { organizational } \\
\text { influences in } \\
\text { terms of culture, } \\
\text { style, structure, } \\
\text { practices, and } \\
\text { competence in } \\
\text { system } \\
\text { development. }\end{array}$} \\
\hline & Informant 2 & $\begin{array}{l}\text { Involved in early } \\
\text { phase and current } \\
\text { project (user } \\
\text { representative) }\end{array}$ & \\
\hline & Informant 3 & $\begin{array}{l}\text { Member of the } \\
\text { steering committee }\end{array}$ & \\
\hline & Informant 4 & $\begin{array}{l}\text { Representative of } \\
\text { the project owner }\end{array}$ & \\
\hline & Informant 5 & Senior adviser & \\
\hline & Informant 6 & \begin{tabular}{|l|} 
External \\
consultant; \\
assisted the \\
Ministry in project \\
evaluation
\end{tabular} & \\
\hline \multirow[t]{2}{*}{$2012-$} & Informant 7 & $\begin{array}{l}\text { Project director in } \\
\text { the organizational } \\
\text { change department }\end{array}$ & \multirow{2}{*}{$\begin{array}{l}\text { Explore lessons } \\
\text { learned and } \\
\text { possible } \\
\text { measures to } \\
\text { reduce the } \\
\text { impact of } \\
\text { organizational } \\
\text { influences on } \\
\text { new information } \\
\text { system projects }\end{array}$} \\
\hline & $\begin{array}{l}\text { Informant } \\
8\end{array}$ & $\begin{array}{l}\text { Newly appointed } \\
\text { project manager }\end{array}$ & \\
\hline
\end{tabular}

The organization's culture also values and expects loyalty, which often leads to a lack of thorough assessments on certain issues or projects. In the worst case, an employee's critical remarks may result in implications on their career or cuts in their department's budget:

"The experts' recommendation was to await the deployment of the new office system; they noted that system is far from finished, and they have warned me that I will meet massive problems. These recommendations were then presented to directors and the executive committee. I got a clear message to be loyal to the decision to deploy the system across the organization. My critical views and 'disloyalty' against management had consequences for me and for my department later on. The annual budget for my department was cut by $50 \%$ in the following fiscal year."
Informants also indicated that work at the Ministry is characterized by a "diffidence culture." Employees are reluctant to "stand out" as they may be stigmatized as "odd" or "uncooperative," and this may have consequences for their professional career. For this project, several participants indicated that they possessed critical comments, but were unwilling to bring these forward, despite the fact that they believed that their comments would benefit the project's progress.

"My interpretation of the conclusions of the evaluation report for the second pilot testing was completely different than management's understanding of this. I interpreted the results to mean that we had to postpone deployment to provide more time for adapting the system to the employees. Management interpreted the results of the evaluation in a completely different and more positive way. They chose to ignore the risks and go for full deployment. My humble attempts to make objections were only met with criticism and resistance."

\subsection{RESISTANCE TO CHANGE}

The core work ethic in the Ministry is traditionally characterized by an unenthusiastic attitude to change. The project represented a new way of working, as well as for conducting management. Of course, this created resistance in the organization:

"I think the project revealed a conflict between structure and individualism. The specialists did not want to be forced to follow a predefined work process. They did not want to change the way of working."

\subsection{RELUCTANCE TOWARDS KNOWLEDGE SHARING}

The Ministry has no tradition of knowledge sharing. Professionals are very protective of their knowledge and information, which in their view is synonymous with power:

"It was not surprising project faced opposition as it would make it easier for employees to share information. Older professionals feared that the new system would increase knowledge sharing and crumble internal power structures. The need to know' principle prevails. You should not have more information than is necessary to solve a problem."

\subsection{RIGID HIERARCHAL FUNCTIONAL STRUCTURE}

Several of the informants attributed the poor performance of the requirement development to the hierarchical power structure in the organization. The Ministry has a traditional functional structure in 
which functional managers exercise full control in their respective departments.

In addition, the Ministry has very little experience of working in projects; matrix or hybrid structures are more or less unknown. There is often a power struggle between functional managers and internal projects regarding the allocation of resources and the prioritization of project tasks.

"It was always a 'battle' with functional managers to get sufficient funding."

The functional structure also prevents functional managers from seeing the whole project. The structure often leads to the "silo-thinking," whereby functional managers are only able to see their own needs.

"Since it is the line that controls it is difficult to see the big picture. The departments' heads are preoccupied with their own issues and priorities. There is a lack of understanding of how the project would benefit the entire organization. I had to fight to get them to see the criticality of end-user involvement and the need for organizational adaptation after deploying the results."

Another challenge that may be associated with balancing the threefold power structure in the Ministry is the complex task of ranking the projects according to their importance in the entire Ministry.

"The Ministry's management prioritizes all projects equally regardless. Therefore it is no easy task to get sufficient and appropriate resources from the top management."

Department managers define what is important in a project, and can thus deprive project managers of the authority they need. It can create a battle of priorities between the project and the departments, although the department managers always win.

"As a manager you cannot get real authority. It is the department manager. It is difficult to manage a project when I do not have authority and project mandate has in fact no real significance."

The organization lacks an organizational unit that can view information systems projects from a strategic perspective.

\subsection{AUTHORITARIAN STYLE DECISION- MAKING}

Several informants expressed that an authoritarian decision-making style is very prevalent in the Ministry. A structure which is built on a "topdown" approach may hinder top management from understanding important perspectives from key stakeholders; in this case, end users. This can have serious consequences and lead to project failure. The direct impact of this factor on the project was the lack of end-user involvement in the initial phase of the project, which was fatal to the project's development and deployment. As such, it was discovered too late that the organization's way of working was not being taken into account in the design of the office management system.

"As head of the department of organizational development, I saw how wrong this IT project was. There was not any kind of analysis or profiling of stakeholders, and the users were not actually included. There was no one who had seen the need to look thoroughly at how the end users are really working, or how we as an organization were interacting with the outside world and with each other."

Another picture of the power system and the "top-down" approach is illustrated with the following quotation:

"It was the prestige of the project. It was in fact the Minister who decided that the project would be deployed despite warnings and risk factors that were described in the evaluation report after the initial pilot phase. No one, not even the steering committee, stood against him. It turned out in retrospect to be a very expensive decision."

All of the informants talked about a lack of real alignment, not only for this project, but as a general phenomenon in the Ministry.

"The top political leadership of the Ministry initiated a major reorganization at the same time it was decided to introduce electronic office management system. It turned out that the reorganization was not successful due to very heavy resistance in the organization. The Minister did not want to include the project as part of organizational change, although it was clear that this would have reduced resistance in the organization. The senior management had therefore no understanding of the totality of the project and how this would affect the organization's way of working and therefore the project lost, in many ways, the necessary commitment from top management leadership."

\subsection{LACK OF PROJECT MANAGEMENT COMPETENCE}

The steering committee was well informed about the complexity of the project - at least formally. Unfortunately, the steering committee tasked with ensuring the quality of the project plans and deliverables did not have what was needed to oversee and control a project of this magnitude and complexity.

"The steering committee did not know what to lead, as it is not competent or qualified to understand the needs of the organization. It was therefore difficult for the steering committee to ask the right and critical questions when it had no knowledge about the project deliverables or its outcome. Members of the steering committee were in reality only puppets. The steering group did not 
therefore exercise the necessary control it is supposed to do."

Another informant concluded that the steering committee had no real expertise:

"It seems that the steering committee of the project failed to understand the complexity of the work."

There was also little acknowledgement in the organization as to the project's work model:

"The Ministry identifies a project as merely a workgroup receiving a mandate with the objective to investigate some issues. In other words, they have no understanding of what a project is really all about or what benefits it should generate."

"The organization does not understand that a project is intended to create changes that should lead to benefits."

In general, specialists take the role of project managers; although they can be a qualified in their own field of expertise, they may not necessarily be the most appropriate project manager. Most often he or she lacks the experience and expertise to manage projects, or simply do not know the project's technical deliveries:

"I was asked to take a project manager job. I had no knowledge of IT projects, but felt I had to say yes in order to avoid any adverse consequences on my professional career later."

Being a project manager gives no special prestige or necessary conditions for career promotion, and so there is little interest in strengthening project expertise among the specialists.

\subsection{DISCUSSIONS}

The findings from the first round of interviews have shown that there were several contributing factors that inhibited the Ministry's ability to perform proper project development management.

\subsection{FUNCTIONAL STRUCTURE}

The organizational structure is hierarchical, and has a strong focus on functional assignments. This structure influences how resources (both financial and human) are allocated and prioritized. Indeed, as noted by many authors (e.g. Kerzner [15], Meredith and Mantel [16],Pinto [17], this type of organizational structure is the most common, and has existed for more than two centuries [15]. Although this type of organization is preferred by many organizations, it may not be very well suited to performing cross-divisional project assignments, as each department tends to overly focus on their own needs and interests in the project [17]. Evidently, the development and the introduction of new office management system is a project that will impact several structures in the Ministry (including the administrative, specialist, and political structure).
It is therefore of a multidisciplinary nature, and requires a more holistic approach during planning, implementation, and deployment. As noted by Meredith and Mantel [16], such a structure does not facilitate a holistic approach to the project because the cross-divisional communication and sharing of knowledge is at best slow and difficult.

\subsection{AUTHORITARIAN STYLE}

The findings show that an authoritarian management style and a "top-down" approach have been used in the project to communicate important decisions. Both the political and administrative leadership of the Ministry have exercised pressure to deploy the new office management system, despite warnings that this approach was risky. Although the organization's autocratic style permits quick decision-making, informants have pointed out that they did not feel that their voices were being heard, and indicated that they felt that this style was not appropriate for this type of project assignment. Prabhakar [18] examined the impact of leadership styles on project performance, and concluded that leaders who employ transformational leadership (i.e. the conscious ability to maneuverer from one leadership approach to another), hold their subordinates' trust, maintain their faith and respect, and appeal to their expectations enjoy more project success. Thite [19] recognized that there is no leadership style that is effective in all project situations. The authoritarian style impacted the Ministry's ability to align the project both upwards and downwards. Several authors have stressed the importance of regarding projects as tools for value creation in an organization [20-22]. In this respect, the findings may suggest that there is a weak or missing alignment between the project and the ambitious plan of restructuring the entire Ministry. Failing to connect the IS project to higher-level objectives may explain the reason behind the lack of enthusiasm and commitment, and the high degree of resistance against the project in the Ministry.

Basu, et al. [9] argue that the involvement of top management is of paramount importance for the successful implementation of major IS projects, with their involvement seemingly more important than that of the project organization.

\subsection{LACK OF PROJECT MANAGEMENT COMPETENCE IN THE PROJECT OWNER ORGANIZATION}

Hong and Kim [10] demonstrated that a project's early phases and its preparation are of most importance for its success. This is especially true in connection with major projects that require changes in an organization. It is very important that management understands their organization's 
structure if it is to succeed in the implementation of complex projects where deliveries have a direct impact on the organization and its working methods. Lack of competence can impact the organization's ability to handle issues such as 1) uncertainty about the intended use/operational scenarios of the product $[23], 2)$ multiplicity of end-users and their expectations to the project outcome, resulting in complications regarding prioritization and selection of requirements, 3) identification of project success criteria and related critical success factors and 4) finally difficulties associated with ambiguity and clarity of requirements expressed by end-users and other stakeholders [24-27]. Commitment of resources, selection of skilled and experienced project leader, assigning proper authority level, providing support and creating accountability are some of the measures the project owner organization could create to provide the right structure to deliver the project as intended.

Hong and Kim [10] have stressed that the successful implementation of IS systems depends upon the organization having a structure that is adapted to the changes. This requires management to commit to the project as a means of organizational changes, rather than technical software installation $[28,29]$. Lack of competence is reflected in the selection of internal project managers who oversee the project, communicate with contractors, etc. Interviewees stated that the Ministry's management or steering committee did not understand the needs of the organization. The results from the interviews showed that a principal shortcoming was that the project did not take into account the changes that have to be implemented in the organization in order for the system to work. However, the department responsible for organizational development was not included in the crucial early stages. The first department only came in after much pressure and many negotiations, by which time it was very late in the project process. This resulted in a lot of resistance from the organization in connection with implementation and application. The organization was neither prepared nor organized in relation to the changes in the system which would lead to new ways of working. According to Hong and Kim [10], this situation is prevalent; they have reported that three of four organizations have had similar problems with organizational changes.

\subsection{CULTURAL CHALLENGES}

Various definitions of organizational culture have been proposed in literature, some examples are shown in Table 2. However, a general consensus has not been achieved because researchers use diverse theoretical approached, assumptions, and interpret similar cultural phenomena in different ways [30].
Table 2. Some definition of organizational culture

\begin{tabular}{|l|l|}
\hline Literature & \multicolumn{1}{|c|}{ Definition } \\
\hline Schein [31] & $\begin{array}{l}\text { A pattern of basic assumptions that are } \\
\text { invented, discovered, or developed by a } \\
\text { given group as it learns to cope with } \\
\text { problems of external adaptation and internal } \\
\text { integration and that have worked well } \\
\text { enough to be considered valid. }\end{array}$ \\
\hline $\begin{array}{l}\text { Hofstede } \\
\text { [32] }\end{array}$ & $\begin{array}{l}\text { The collective programming of the mind } \\
\text { that distinguishes the members of one } \\
\text { organization from others }\end{array}$ \\
\hline $\begin{array}{l}\text { Alvesson } \\
{[33]}\end{array}$ & $\begin{array}{l}\text { An umbrella concept for a way of thinking } \\
\text { which takes a serious interest in cultural and } \\
\text { symbolic phenomena. }\end{array}$ \\
\hline
\end{tabular}

Pinto [17] defines the organizational culture as the third contextual variable in how projects are managed effectively. Culture is the unwritten rules of behaviors or norms that are shared by a subset of the organization, and thus which shape and guide the behavior of employees. According to Pinto [17], culture is a product of many factors, including the type of work, environment, geography, reward systems, procedures, key members, and critical incidents. Butler [34] has described systems development practices in large multinational organizations, where the social matrix and identity of the organization are shaped by a dominant group of employees, namely engineers.

All these factors shape the working culture of an organization; therefore changing the organizational culture is not a matter of will. Organizational culture affects how departments are expected to interact; it influences the extent of employees' commitment to the goals of the project, as well as influencing the project planning process, and how managers evaluate performance.

Doolin [35] and Wilson and Howcroft [36] have conducted empirical studies which show that the introduction of a system can be problematic in situations where workers have a strong professional culture, identity, autonomy, or level of unionization. Problems can arise when the whole system - or parts of it - is perceived as challenging traditional professional values, roles, status, and work conditions, undermining or threatening individual or collective identities, and making work practices more transparent.

The findings show that the work culture in the Ministry can be described according to two features:

1) Conformist working culture. The findings show that the Ministry's organizational culture is an obstacle to the effective involvement of end users. The Ministry's career promotion mechanism (a reward system) may also impact its organizational culture, creating a culture of diffidence in which loyalty is forced upwards. The question is how the Ministry can overcome this 'diffidence culture,' 
which seems to be inhibitory to the requirement process in which new and possibly unpopular decisions have to be adopted. As such, the Ministry's culture seems to prevent real and effective decision-making, and so the threshold to tell 'where the shoe pinches' should be lower.

Conformity is a subject's behavior or attitude following those of the object [37]. The object can be organizations, individuals or subgroups. Conformity involves social pressures, which relate to the influence that individuals have over one other [38]; examples are compliance pressures, obedience and peer pressure.

Normative conformity is the result of normative influence and has been given significant attention in literature Normative conformity is the result of a strategic effort of the individual to be accepted and to avoid social rejection, hostility or disapproval from others [39], regardless of whether the object of conformity is right of wrong [38]. Normative conformity has a direct impact on the organization's creative and innovative capacity, and consequently it affects the organization's responses to stressful situations and changes, as Pech [40] suggests. The author (ibid) explains that a dominant culture of conformity perpetuates the status quo and followership. Chong and Syarifuddin [41] suggest that a project manager that experience conformity pressure has more tendency to continue a failing project.

2) Resistance to change. According to the informants, the prevailing culture in the Ministry is one in which innovation and new thinking is rarely promoted. Neumann and Leira [42] studied several cases of organizational change in the Ministry, and concluded that changes in the Ministry originate externally, rather than from within the organization itself. The Ministry has a traditional work culture that fights for the status quo, thereby inhibiting the introduction of new ways of working. This appeared in at its most marked in connection with the introduction of the new office management system. Resistance to change has been defined as "an adherence to any attitudes or behaviours that thwart organisational change goals and "any conduct that serves to maintain the status quo in the face of pressure to alter the status quo" [43]. The author (ibid) have shown that resistance to change is correlated with lack of affective commitment among employees. Affective Organizational Commitment (AOC) occurs when the goals of the individuals and the organizations become increasingly integrated or the identity of the individual is linked to the organization [44]. AOC is believed to encourage behaviors that are beneficial for the organization such as performance and intention to stay in the organization [45]. Other forms of commitment have been proposed in the organizational literature [i.e. 46 , 47] such as continuance and normative commitment. However, affective commitment is considered the one with the strongest and most consistent relation to desirable outcomes [3].

One reason for the project's lack of acceptance was resistance within the Ministry, which might be directly related to affective organizational commitments. The top administrative leader and several older expeditionary leaders found it was not necessary to learn and use the office management system, and continued to send handwritten memos and instructions for their secretaries to type. In the wake of this resistance to new working methods, several other departments completely sabotaged the project as a result of top management's actions. In the Ministry, the type of work conducted is quite complex: it is based on political and cross-cultural knowledge, and therefore persevering relationships and ensuring stability is of vital importance. This cultural factor goes some way to explain the skepticism towards the new system. The ability to share knowledge and information is a characteristic of an organization's working culture, yet the interviews suggested that there is culture of withholding information. Milne [48] emphasized that one of the biggest challenges for a knowledge organization is knowledge sharing: "it is the fundamental requirement of a knowledge-based organization. In particular, organizations where there is a fortified culture among staff to safeguard information, rather than sharing it with others." Umble, et al. [49] highlight how an organizational culture that is receptive to change and continuous improvement can facilitate the implementation and acceptance of changes associated with an ERP system.

\section{CONCLUSIONS AND RECOMMENDATIONS}

The findings of the first round of interviews have shown that the compound effect of the Ministry's organizational structure, level of competence, and working culture have greatly influenced the performance and outcome of the project.

\subsection{END USERS' LEVEL OF INVOLVEMENT DURING THE EARLY PHASE}

The findings suggest that a major obstacle to enduser involvement is a combination of the conformist working culture in the organization and the total lack of project management competence in the Ministry. The Ministry's career promotion mechanism (reward system) may have also impacted its organizational culture, and may have created a culture of 
diffidence, forced conformity and loyalty moving upwards. As such, the Ministry's culture seems to prevent real and effective involvement.

\subsection{THE INABILITY TO PREPARE AND COMMIT THE ENTIRE ORGANIZATION TO THE CHANGES BROUGHT ABOUT BY THE NEW SYSTEM}

The findings suggest that a combination of the Ministry's authoritarian style and inherent culture of resistance to change have impacted on its ability to effectively prepare and commit stakeholders to the project and the changes it will create in the organization. Failing to align the project both upwards and downwards explains the reasons behind this lack of enthusiasm, and the resistance against the project during planning and deployment. In the Ministry, the type of work conducted is quite complex and is of a political and cross-cultural nature; therefore preserving relationships and stability is of vital importance. This cultural factor perhaps explains the skepticism towards the new system.

\subsection{THE ABILITY TO TAKE MANAGERIAL DECISIONS BASED ON HOLISTIC UNDERSTANDING OF THE PROJECT}

The Ministry's threefold power structure has produced a rigid authoritarian and functional management structure that has directly impacted on both the organization's ability to provide support and resources, and their means to plan and execute according to best practices. The structure has a strong focus on assignments, and this focus has influenced how resources - both financial and human - were allocated and prioritized in the project. These findings are consistent with the project management literature, which affirms that this structure does not facilitate a holistic approach to the project, as the cross-divisional nature of communication and knowledge sharing is slow and difficult at best. A total lack of competence regarding the project's principles also created a situation that made it difficult for the steering group to exercise control. This was reflected in the selection of internal project managers for overseeing the project, communicating with contractors, and so forth.

Did the Ministry learn anything from the failed first phase (2001-2011)?

The period 2001-2011 has been judged a learning phase for the Ministry. In 2011, the Ministry decided that "something" has to be done in order to put the information system to effective use. In 2012, a new project director was appointed, who was given the mandate to take the failed information management system to the "next phase." Efforts were made and there are some general outcomes that have already taken place in the new phase of the project. These efforts include:

The old system was replaced with an "off the shelf" system with no special development phase or state-of-the-art product.

The new system is the same as at other ministries. It is thus more in tune with what the other departments are using, which facilities interaction with other ministries and eliminates the need for modifications to interfaces.

A proper requirement process has been launched and implemented.

There have been several "fights," and a number of efforts have been made to establish acceptance of a sound and proper context for performing project requirement management. This was a critical element, as the Ministry's top management (project owner) did not understand that the requirement process was an integral part of the process.

Furthermore, the informants have reported that the following concrete measures have been undertaken:

1) Improving project management skills in the owner organization

A new project director has been appointed, who has demonstrated solid managerial skills and strong results in restructuring and modernizing the organization. The project director agreed to take on the position on the condition that a project manager runs the "next phase." The newly appointed project manager was an external expert, but had been working on various projects with the Ministry as an external project manager. Besides this, the new project manager knew and understood the working culture without being a part of it. Therefore the project manager can pinpoint the obstacles/problems with the previous system without losing credibility or jeopardizing his own career. The new project manager is a sharp observer who appreciates the need to involve end users, as well as the awareness of the cultural and the structural barriers in the Ministry. The project manager has thus a unique combination of strong project managerial skills and an understanding of the internal structure and culture of the organization.

2) Investing in project requirement process at an early stage

The top priority for the new project team was to establish a valid system for performing requirement management. They wanted to document, analyze, validate, and control the requirements according to established best practices, so the first thing they did was to define its vision and scope. The vision for the new information management system was to see the new system as an integrated part of end users' work processes. The way the end user utilizes and 
processes information on a daily basis should be the starting point of integrating the system into their work process.

Furthermore, the new project manager determined that, if the new system was to be a success, it should be mandatory for all employees. No end users should get away with not using the system in their daily work (tasks). As such, the system had to be viewed by the end users in a completely new way: they had to feel that the system was an integrated part of their daily workflow, and the information systems' functions should be integrated into their work process. It should not been seen as a "painful" add-on (as in the past), or as a complicated and difficult process that was hard to understand or use in their daily work.

The project manager documented the basic requirements of the end users through different methods, such as observation, interviews, workshops, etc. Moreover, all the leaders including those at the critical middle-level management level - were interviewed. The middlelevel leaders should accept the new system, as they are now role models for the rest of the organization. Another success criterion of the project was the full acceptance of the new system from the middle-level management.

"Every manager on this level should be 'on board'."

\subsection{FINAL REMARKS AND SUGGESTIONS FOR FUTURE RESEARCH}

This case study indicates that the impact of organizational influences on project outcomes should not be underestimated. This case study also demonstrates that some of these organizational influences are addressable through concrete and direct measures, such as enhancing project management competences, the allocation of better resources, better funding, and through applying structuring methods for determining requirements. However, there are other factors that are usually deeply rooted in employees' procedures, minds and hearts, which limit the organization's ability to involve, align, and manage a project's key stakeholders in an appropriate manner. Therefore, the author's main conclusion is that these factors remain unresolved. These include an absence of a holistic approach and unified way of managing projects in the Ministry. Projects are still run within the boundary of a line organization, and this has caused the Ministry to fail in seeing projects as a part of organizational development and knowledge sharing in the Ministry. Also, organizational development and attempts to change the way people work and interact is still met with greater resistance to change within the organization.

In our future research work, we will study the underlying causes and impacts on information systems projects at the Ministry, as resistance to change is still very much rooted in their work ethic. Further studies should also look into the ways in which external political and environmental factors contribute to this factor, particularly how the threefold power structure contributes to resistance to change. Research should also investigate possible ways to enhance project maturity in the organization so as to enhance project development.

\section{REFERENCES}

[1] B. A. Hussein, K. Hafseld, Impact of organizational factors on information system project, in Proceedings of the $7^{\text {th }}$ IEEE International Conference on Intelligent Data Acquisition and Advanced Computing Systems (IDAACS'2013), Berlin, 12-14 September 2013, Vol. 02, pp. 591-596.

[2] PMBoK, A Guide to the Project Management Body of Knowledge (PMBOK® guide), Fifth Edition, Project Management Institute, Inc., 2013.

[3] L. Mei-Yung, A. Chong, S. T. Ng, and M. C. K. Cheung, Demystifying stakeholders' commitment and its impacts on construction projects, Construction Management and Economics, (22) 7 (2004), pp. 701-715.

[4] J. J. Fowler and P. Horan, Are information systems' success and failure factors related? An exploratory study, Journal of Organizational and End User Computing, (19) 2 (2007), pp. 1-22.

[5] J. K. Pinto and J. E. Prescott, Variations in critical success factors over the stages in the project life cycle, Journal of Management, (14) 1 (1988), pp. 5-18.

[6] L. McLeod and S. G. MacDonell, Factors that affect software systems development project outcomes, ACM Computing Surveys, (43) 4 (2011), pp. 1-56.

[7] S. Robertson and J. Robertson, Mastering the Requirements Process: Getting Requirements Right, Upper Saddle River, N.J.: AddisonWesley, 2012.

[8] B. Hughes and M. Cotterell, Software Project Management, London: McGraw-Hill, 2009.

[9] V. Basu, E. Hartono, A. L. Lederer, and V. Sethi, The impact of organizational commitment, senior management involvement, and team involvement on strategic information systems planning, Information \& Management, (39) 6 (2002), pp. 513-524. 
[10] K.-K. Hong and Y.-G. Kim, The critical success factors for ERP implementation: an organizational fit perspective, Information \& Management, (40) 1 (2002), pp. 25-40.

[11] P. Milne, Motivation, incentives and organisational culture, Journal of Knowledge Management, (11) 6 (2007), pp. 28-38.

[12] B. A. Hussein, G. Pigagaite, and P. P. Silva, Identifying and dealing with complexties in new product and process development projects, Procedia - Social and Behavioral Sciences, (119) (2014), pp. 702-710.

[13] N. Iivari, Enculturation of user involvement in software development organizations - an interpretive case study in the product development context, in Proceedings of the third Nordic Conference on Human-Computer Interaction, Tampere, Finland, (October 23-27, 2004), pp. 287-296.

[14] R. Coughlan, Employee Loyalty as Adherence to Shared Moral Values, Journal of Managerial Issues, (17) 1 (2005), pp. 43-57.

[15] H. Kerzner, Project Management : A Systems Approach to Planning, Scheduling, and Controlling, Hoboken, N.J.: Wiley, 2009.

[16] J. R. Meredith and S. J. Mantel, Project Management : A Managerial Approach, Hoboken, N.J.: Wiley, 2010.

[17] J. K. Pinto, Project Management: Achieving Competitive Advantage, Boston: Pearson Prentice Hall, 2012.

[18] G. P. Prabhakar, Switch leadership in projects an empirical study reflecting the importance of transformational leadership on project success across twenty-eight nations, Project Management Journal, (36) 4 (2005), pp. 51-61.

[19] M. Thite, Leadership styles in information technology projects, International Journal of Project Management, (18) 4 (2000), pp. 235-241.

[20] M. Winter, C. Smith, P. Morris, and S. Cicmil, Directions for future research in project management: The main findings of a UK government-funded research network, International Journal of Project Management, (24) 8 (2006), pp. 638-649.

[21] H. Ingason and H. Jónasson, Contemporary knowledge and skill requirements in project management, Project Management Journal, (40) 2 (2009), pp. 59-69.

[22] T. Williams and K. Samset, Issues in front-end decision making on projects, Project Management Journal, (41) 2 (2010), pp. 38-49.

[23] L. Jun, W. Qiuzhen, and M. Qingguo, The effects of project uncertainty and risk management on IS development project performance: A vendor perspective,
International Journal of Project Management, (29) 7 (2011), pp. 923-933.

[24] E. Kamsties, D. M. Berry, and B. Paech, Detecting ambiguities in requirements documents using inspections, in Proceedings of the First Workshop on Inspection in Software Engineering (WISE'01), 2001, pp. 68-80.

[25] P. R. Duimering, B. Ran, N. Derbentseva, and C. Poile, The effects of ambiguity on project task structure in new product development, Knowledge and Process Management, (13) 4 (2006), pp. 239-251.

[26] R. R. Young, Effective Requirements Practices, Boston, Mass.: Addison-Wesley, 2001.

[27] R. R. Young, Project Requirements : A Guide to Best Practices, Vienna, Va.: Management Concepts, 2006.

[28] M. L. Korzaan, The influence of commitment to project objectives in information technology (IT) projects, The Review of Business Information Systems, (13) 4 (2009), pp. 89-97.

[29] L. Zhai and J. Xu, Systematic thinking on success criteria of IS/IT projects, Journal of Fudan University (Natural Science), (42) (2003), pp. 749-54.

[30] W. Belassi, A. Z. Kondra, and O. I. Tukel, New product development projects: The effects of organizational culture, Project Management Journal, (38) 4 (2007), pp. 12-24.

[31] E. H. Schein, Organizational Culture and Leadership, $3^{\text {rd }}$ edition, San Francisco, CA: Jossey-Bass, 1990.

[32] G. Hofstede, Cultures and Organizations: Software of the Mind, UK: McGraw-Hill, 1991.

[33] M. Alvesson, Understanding Organizational Culture, London, GBR SAGE Publications Ltd. (UK), 2002.

[34] T. Butler, An institutional perspective on developing and implementing intranet- and internet-based information systems, Information Systems Journal, (13) 3 (2003), pp. 209-231.

[35] B. Doolin, Power and resistance in the implementation of a medical management information system, Information Systems Journal, (14) 4 (2004), pp. 343-362.

[36] M. Wilson and D. Howcroft, Reconceptualising failure: social shaping meets IS research, European Journal of Information Systems, (11) 4 (2002), pp. 236-250.

[37] G. Song, Q. Ma, F. Wu, and L. Li, The psychological explanation of conformity, Social Behavior and Personality, (40) 8 (2012), pp. 1365-1372.

[38] F. T. DeZoort and A. T. Lord, A review and synthesis of pressure effects research in 
accounting, Journal of Accounting Literature, (16) (1977), pp. 28-85.

[39] M. J. Hornsey, L. Majkut, D. J. Terry, and B. M. McKimmie, On being loud and proud: Non-conformity and counter-conformity to group norms, The British Journal of Social Psychology, (42) 3 (2003), pp. 319-335.

[40] R. J. Pech, Reflections: Termites, group behaviour, and the loss of innovation: Conformity rules!, Journal of Managerial Psychology, (16) 7 (2001), pp. 559-574.

[41] V. K. Chong and I. Syarifuddin, Escalation of commitment to unprofitable projects: An experimental investigation of the effect of conformity pressure and self-esteem, Accounting, Accountability \& Performance, (16) $1 / 2$ (2010), pp. 1-23.

[42] I. B. Neumann and H. Leira, Aktiv og Avventende: Utenrikstjenestens Liv 1905-2005. Oslo: Pax, 2005.

[43] K. McKay, J. R. C. Kuntz, and K. Näswal, The effect of affective commitment, communication and participation on resistance to change: the role of change readiness, New Zealand Journal of Psychology, (42) 2 (2013), pp. 57-68.

[44] R. T. Mowday, R. M. Steers, and L. W. Porter, The measurement of organizational commitment, Journal of Vocational Behavior, (14) 2 (1979), pp. 224-247.

[45] M. Riketta and A. Landerer, Organizational commitment, accountability, and work behavior: A correlational study, Social Behavior and Personality, (30) 7 (2002), pp. 653-660.

[46] N. J. Allen and J. P. Meyer, Affective, continuance, and normative commitment to the organization: an examination of construct validity, Journal of Vocational Behavior, (49) 3 (1996), pp. 252-276.
[47] Y. Wiener, Commitment in organizations: A normative view, Academy of Management. The Academy of Management Review (pre-1986), (7) 3 (1982), pp. 418-428.

[48] P. Milne, Motivation, incentives and organisational culture, Journal of Knowledge Management, (11) 6 (2007), pp. 28-38.

[49] E. J. Umble, R. R. Haft, and M. M. Umble, Enterprise resource planning: Implementation procedures and critical success factors, European Journal of Operational Research, (146) 2 (2003), pp. 241-257.

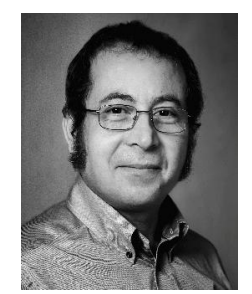

Bassam A. Hussein is an Associate Professor at the Department of Production and Quality Engineering, the Norwegian University of Science and Technology in Trondheim, Norway. His research interests include: project success, application of gaming simulations, e-learning, requirements management, organizational learning, and assessment of learning. He teaches project and requirements management and has been involved in the design, development, and implementation of a wide range of corporations' customised education programmes in project management.

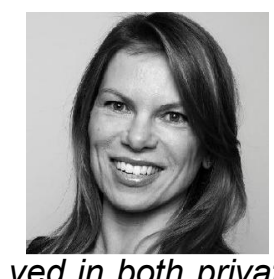

Kristin H. Hafseld earned her MBA from Norwegian School of Economics (Bergen, Norway). She has a wide and extensive experience in international relations and multilateral negotiations and ser-

ved in both private and governmental organisations. She has held various positions in the private sector, among them served as project manager and a corporate social responsibility consultant at a major Norwegian finance corporation. She is taking her Master's degree in Project Management at the Norwegian University of Science and Technology, Norway. 